\title{
Case Study: Chromoblastomycosis
}

\section{Sangeetha Bobba*}

MBBS (Monash) FRACGP DCH Cert SH \& FPA GradCert MH, Australia

*Corresponding author: Sangeetha Bobba, MBBS (Monash) FRACGP DCH Cert SH \& FPA GradCert MH, Australia, Tel: +61410947645; E-mail: sangeetha.bobba@gmail.com

Rec Date: May 22, 2014, Acc Date: Jul 11, 2014, Pub Date: Jul 14, 2014

Copyright: $\odot 2014$ Bobba S. This is an open-access article distributed under the terms of the Creative Commons Attribution License, which permits unrestricted use, distribution, and reproduction in any medium, provided the original author and source are credited.

\section{Case Study}

Raj, aged 35 years presented to a tertiary hospital in Southern India with a skin lesion covering his right foot and ankle. He complained of his foot being intensely itchy and this interfering with his work as a sugar cane farmer. Raj stated the lesions had been present for years and only sought medical attention due to persistence from his wife. The skin condition initially arose approximately $10-15$ years ago starting as a solitary bump and gradually extended to involve the entire foot and ankle. During this period he continued working on his sugar cane farm and described the appearance of satellite lesions. Raj stated he experienced some pain and had some difficulty walking but no other associated symptoms. He had no previous medical attention or treatment for his skin condition prior to this presentation. Raj had no other significant medical history and was not taking any medications. He had no allergies and no relevant family history.

On physical examination of his right foot and ankle there was multiple verrucous nodules of varying sizes with a cauliflower-like appearance associated with overlying crusting on the background of plaques and elephantiasis of the right foot. Some ulceration of lesions was also noted (Figure 1). The diagnosis of this condition was made on clinical examination and confirmed on skin biopsy and fungal culture which determined the causative agent as being Fonsecaea pedrosoi. Raj was commenced on a combined regime of oral Itraconazole and Terbinafine in addition to surgical excisions. However due to his late presentation, following several months of this treatment there was no significant improvement of his condition hence, amputation of his right foot was being considered as the definitive treatment.

\section{Discussion}

The diagnosis is chromoblastomycosis, a skin condition more common in the tropical or subtropical climates of Asia and South America [1]. Chromoblastomycosis is a chronic subcutaneous mycosis caused by pheoid or dematiaceous fungi with Fonsecaea pedrosoi being the most common causative organism worldwide [1]. Other fungal causes include Fonsecaea compacta, Fonsecaea monophora, Phialophora verrucosa, Cladophialophora carrionii, Rhinocladiella aquaspersa and Exophiala jeanselmei [2]. Traumatic inoculation of the fungi usually occurs from fungi inhabited thorns or splinters of decaying wood and plants. Hence, it commonly affects the lower limbs of farmers or labourers in rural areas as they are exposed to frequent local traumas and exposure to fungi inhabited soil and plants particularly if they work barefoot [1]. Chromoblastomycosis usually initially commences as a solitary papule and progresses to plaques with nodular verrucous lesions. Secondary infection can cause ulceration and purulent discharge. Lymphadenopathy and elephantiasis can occur in severe cases [3].

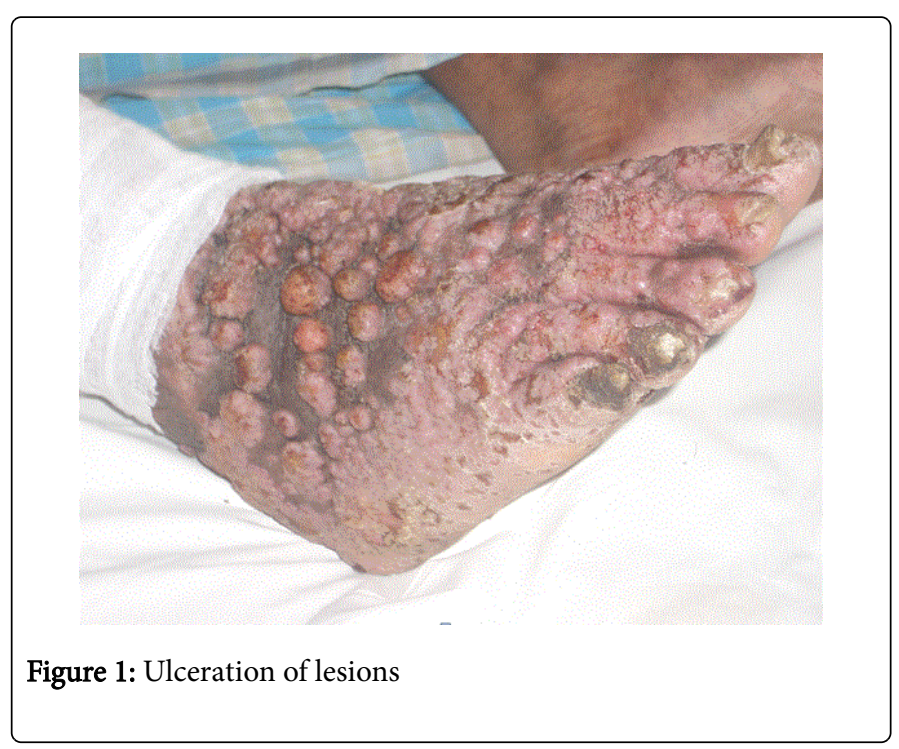

The differential diagnoses for chromoblastomycosis include:

Cutaneous lymphoma

Verrucous tuberculosis

Fixed sporotrichosis

Lacaziosis

Leishmaniasis

Blastomycosis

Paracoccidioidomycosis

\section{Verrucae}

Squamous cell carcinoma [2]

The diagnosis is confirmed by skin biopsy and fungal culture to isolate the causative organism. A skin biopsy with the presence of fumagoid cells or Medlar bodies is characteristic and confirms the diagnosis of chromoblastomycosis [2].

The treatment of chromoblastomycosis is difficult as it often requires months or years of antifungal therapy and can be refractory to medical treatment. Six months of antifungal treatment can improve the condition however, relapse is common [2]. If medical treatment proves insufficient surgical measures may be required.

The treatment options of chromoblastomycosis include:

Oral Itraconazole

Oral Terbinafine 
Page 2 of 2

\section{Curettage}

Electrodesiccation

Cryosurgery

Surgical excisions

Amputation of the lower limb is the last resort if all other treatments have failed [2]

Prognosis is improved by utilising a combined regime of Itraconazole and Terbinafine or utilising both surgical and antifungal treatments [4]. Other treatments resulting in variable outcomes and not widely utilized include oral 5-fluocytosine, oral potassium iodide, high dose vitamin $\mathrm{D}$, intravenous amphotericin $\mathrm{B}$ and local heat therapy [2].

Chromoblastomycosis can lead to potentially serious complications, squamous cell carcinoma being the concurrent diagnosis to rule out with biopsy. Squamous cell carcinoma needs to be highly suspected in chromoblastomycosis presenting with chronic ulcerated lesions [5]. Other complications include secondary infection, lymphoedema or elephantiasis and lymphatic and haematogenous dissemination [1].

Patients with immunodeficiency, cancer, HIV infection or taking immunosuppressive medications may be at risk of complications or dissemination hence requiring aggressive treatment and close monitoring [2].

The majority of chromoblastomycosis cases occur in the tropical and subtropical areas of Asia and South America with Brazil and Madagascar having the highest number of reports [4]. Although not as common, cases have been reported in Australia hence awareness of the condition is important [6]. Cladophialophora carrionii is often the causative fungi in Australia as the organism is found in arid and semiarid areas [2]. Recent definitive numbers of chromoblastomycosis cases in Australia have not been published however the condition is more common in Queensland and the Northern Territory where a higher degree of suspicion is needed $[7,8]$.

\section{References}

1. Yap FBB (2010) Chromoblastomycosis. International Journal of Infectious Diseases 14: e543-e544.

2. Torres-Guerrero E, Isa-Isa R, Isa M, Arenas R (2012) Chromoblastomycosis. Clinics in Dermatology 30: 403-408.

3. Queiroz-Tellez F, Esterre P, Perez-Blanco M, Vitale RG, Salgado CG, et al. (2009) Chromoblastomycosis: an overview of clinical manifestations, diagnosis and treatment. Med Mycol 47: 3-15.

4. Chandran V, Sadanandan M, Sobhanakumari K (2012) Chromoblastomycosis in Kerala, India. Indian J Dermatol Venereol Leprol 78: 728-733.

5. Roy AD, Das D Deka M (2013) Chromoblastomycosis - A Clinical Mimic of Squamous Carcinoma. Australas Med J 6: 458-460.

6. Ameen M (2009) Chromoblastomycosis: Clinical Presentation and Management. Clinical and Experimental Dermatology 34: 849-854.

7. Currie BJ, Carapetis JR (2000) Skin Infections and Infestations in Aboriginal Communities in Northern Australia. Australas J Dermatol 41: 139-143.

8. Powell EE (1952) A Survey of Chromoblastomycosis in Queensland. Aust J Dermatol 1: 214-222. 